\title{
Learning to Notice Important Student Mathematical Thinking in Complex
}

Classroom Interactions

Shari L. Stockero ${ }^{a}$, Rachel L. Rupnow ${ }^{b}$, and Anna E. Pascoe 


\section{Learning to Notice Important Student Mathematical Thinking in Complex Classroom Interactions $^{\mathrm{a}}$}

Noticing students' mathematical thinking is a key element of effective instruction, but novice teachers do not naturally engage in this practice. Prospective secondary school mathematics teachers were engaged in an intervention grounded in analysis of minimally edited video from local secondary school mathematics classrooms; the goal was to support their ability to notice important student thinking within the complexity of instruction. Evidence of participants' learning in five iterations of the intervention is discussed, including their focus on student mathematical thinking, their ability to discuss the mathematics in that thinking, and their ability to notice particular high-leverage instances of student thinking.

\section{Introduction}

A key distinction between novice and expert teachers is their ability to notice what is important in complex classroom situations (Berliner, 2001). One particularly important focus of teacher noticing is student mathematical thinking, since teachers' use of student ideas has been identified as an important element of effective mathematics instruction (e.g., Anthony, Hunter, \& Hunter, 2015; Jaworski, 1994; National Council of Teachers of Mathematics [NCTM], 2014) and has been linked to increased student learning (e.g., Fennema et al., 1996). Novice teachers, however, do not naturally focus their attention on making sense of student ideas (Jacobs, Lamb, \& Philipp, 2010); rather, they tend to focus on other aspects of the classroom such as management (Star \& Strickland, 2008) and teacher actions (Santagata, Zannoni, \& Stigler, 2007), often failing to make distinctions among the pedagogical value of these different events (Sherin \& van Es, 2005). Fortunately, teachers' ability to notice student mathematical thinking is a skill that can be learned (e.g., Jacobs et al., 2010; Sherin \& van Es, 2005) and has thus become a focus in many teacher preparation programs. Incorporating learning-to-notice activities in structured settings is part of a growing movement to provide "opportunities to practice elements 
of interactive teaching in settings of reduced complexity" (Grossman \& McDonald, 2008, p. 190).

Prospective teacher (PT) noticing interventions have typically taken place late in teacher preparation programs, during mathematics pedagogy courses or the practicum semester (Roth McDuffie et al., 2014; Mitchell \& Marin, 2015; Santagata, Zannoni, \& Stigler, 2007; Schack et al., 2013). It is worth considering whether noticing skills can be developed at the beginning of a teacher education program, however, because noticing student ideas is a key component of teaching expertise and foundational to student-centered instruction (Sherin, Jacobs, \& Philipp, 2011). Developing such skills early on could support what Franke and Kazemi (2001) have called generative growth - the ability to build on current understanding to generate new knowledge - during later phases of the program.

School-based field experiences that take place early in a teacher education program are one promising context for developing noticing skills because they provide a venue for real time observation and interaction with students in a practice-based setting. Focusing on a construct such as noticing also has the potential to address some of the criticisms of such experiences, including that they often have ill-defined goals that are not communicated to school-based mentors (Leatham \& Peterson, 2010), lack adequate support to allow PTs to engage in meaningful observation of teaching and learning (Masingila \& Doerr, 2002), and support what is currently being done in classrooms rather than helping PTs consider new possibilities for instruction (Philipp et al., 2007). In this work, we re-conceptualized an early field experience as a context to develop PTs' abilities to notice student mathematical thinking. Doing so, we conjectured, would articulate a clear goal for learning, provide a structure to support productive observation, and lay a foundation for student-centered instruction. 
The intervention in this study was designed to promote PTs' noticing of high-leverage instances of student thinking that could be used by a teacher to support students' understanding of important mathematics. Key elements of the intervention included use of whole-class, teacherperspective video; engaging PTs in fine-grained video analysis; and substantial involvement of a teacher educator to help PTs make sense of what they observed in the classroom. In this paper, we focus on understanding the effects of this learning-to-notice intervention by examining the question: In what ways does prospective teacher noticing of high-leverage instances of student mathematical thinking change as a result of a noticing intervention during an early field experience course?

\section{Connections to the Literature}

In recent years, a growing body of research has emerged around the construct of teacher noticing (van Es \& Sherin, 2002). This construct's importance stems from its centrality to student-centered mathematics instruction; in short, teachers cannot intentionally act upon student ideas they do not notice (Sherin et al., 2011). Although noticing research has focused on teachers' attention to a range of features of classroom instruction, we limit our discussion to studies that have a focus consistent with our own work — noticing student mathematical thinking. We discuss how such noticing has been studied, how this skill has been developed with PTs, and the emerging body of literature related to the use of frameworks to scaffold teacher noticing.

\section{Ways of Studying Teacher Noticing}

Studies of teacher noticing have varied both in the medium used and the mathematical focus. A common means of studying noticing is engaging teachers in analysis of student written work to document what they notice about students' mathematical thinking. For example, Fernández, Llinares, and Valls (2013) used student work to document what prospective primary 
teachers noticed relative to students' ability to reason proportionally, while Haltiwanger and Simpson (2014) used this medium to document what prospective secondary teachers noticed about students' thinking related to extending a pattern. Others have used short video excerpts of diagnostic interviews (Schack et al., 2013) or classroom instruction (Walkoe, 2015); these interventions were related to noticing early arithmetic reasoning and algebraic reasoning, respectively. Jacobs et al. (2010) used both student written work and a short video clip to assess teachers' highest level of noticing related to students' problem solving with whole-number operations when they interacted with either medium. In all of these studies, the student thinking available to notice was narrowed in some way, either through the medium or the mathematical focus. Constraining what is available to notice has advantages, but it also has limitations. Constraining noticing to a specific mathematical topic allows for assessment against specific mathematical criteria (e.g., noticing stages of learning, common strategies), but requires that frameworks be developed for each mathematical topic (Fernández et al., 2013; Walkoe, 2015). Constraining noticing by narrowing the medium — using written work or a short video clip_makes interventions more manageable (Schack et al., 2013), but is very different from the noticing that takes place during complex classroom interactions. In short, it is not clear whether skills developed in a narrowed noticing context will transfer to noticing in the classroom.

Video excerpts with a range of mathematical foci have been used to both develop and document noticing in a way that more closely approximates the noticing that teachers engage with in a classroom. Such studies have typically utilized short researcher-selected video clips, either from available sources (Roth McDuffie et al., 2014) or from participants' own classrooms (Sherin \& van Es, 2005; van Es, 2011). Some recent studies have examined teacher noticing using media that encapsulates the full complexity of classrooms. For example, Barnhart and van 
Es (2015) assessed the outcomes of a video-based course focused on analyzing instruction by examining what prospective science teachers noticed in their own student teaching video. Mitchell and Marin (2015) had students analyze 20-minute segments of their own student teaching videos, while Vondrová and Žalská (2015) considered prospective mathematics teachers' noticing using videos from the TIMSS 1999 Video Study. Because the content and focus of the videos in these studies varied, they required different analysis techniques. In such studies, it is common for researchers to assess noticing using frameworks that characterize aspects of noticing such as what (different actors and topics) and how (level of description or analysis) teachers notice (e.g., van Es \& Sherin, 2008). A similar analysis of components of teacher noticing was used in the current study that incorporated full-length classroom video, but additional analysis techniques were also used to determine whether the participants were noticing particular types of instances that transcend specific mathematics content or courses - those that have significant potential to support students' mathematical learning.

\section{Prospective Teacher Noticing Interventions}

Some researchers have tried to promote PT noticing through targeted interventions. Those designed to focus on professional noticing of children's mathematical thinking (Jacobs et al., 2010) have mainly developed noticing skills through analysis of short video excerpts, typically during a mathematics pedagogy course. Schack et al.’s (2013) intervention engaged PTs with video clips of diagnostic interviews with children over five class periods to develop their ability to notice children's thinking about early numeracy. Roth McDuffie et al. (2014) engaged PTs in analysis of four to five video clips to develop noticing through four lenses: teaching, learning, tasks, and power and participation, while Walkoe (2015) developed noticing skills through analysis of seven video clips, incorporating individual online video tagging 
assignments and video club meetings. Common among all of these interventions was the use of a small number (4-7) of short video excerpts, small and whole group discussion about salient features of the video, and some sort of prompt or framework to guide noticing. Evidence across these interventions suggests that PTs' noticing skills can be successfully developed through targeted interventions, although as noted by Schack et al. (2013), they did so in "environment(s) in which the number of salient features was limited and, therefore, a manageable focus for discussions" (p. 395). Mathematics classrooms, however, are not limited in the scope of what might be noticed, raising questions of whether PT noticing can be supported in a more complex context that simulates classroom noticing; this is a focus of the current study.

\section{Viewing Frameworks to Scaffold Noticing}

Although many early noticing interventions used general prompts to elicit and develop teacher noticing, such as "What did you notice?" (e.g., Sherin \& van Es, 2005; van Es, 2011), there is accumulating evidence to suggest that video-based noticing interventions might be enhanced by scaffolding noticing in a more targeted way. Roth McDuffie and colleagues (2014) used a series of targeted questions to prompt PTs to view video through four different lenses and concluded that these scaffolds "seemed to support [PTs'] noticing at higher levels" (p. 267), including making connections between key components of teaching and learning. Santagata (2011) also found that posing targeted questions focused on the relationship between a teacher's actions and students' learning of mathematics supported teachers in providing more in-depth analyses of these interactions.

More recently, interventions have used more formal noticing frameworks to support PTs' noticing of specific features of classroom discourse. Mitchell and Marin (2015) used a modified version of the Mathematical Quality of Instruction (MQI) (Hill et al., 2008) instrument as a 
framework to help PTs notice important aspects of a lesson and use evidence to support their analyses and interpretations. They found that PTs' noticing became more aligned with elements of instruction that are the focus of the MQI. Additionally, they conjectured that discussion about the definitions of the MQI codes helped develop an understanding of what elements of effective instruction might look like during a lesson.

Walkoe (2015) used an Algebraic Thinking Framework developed for her study to focus PTs on aspects of algebraic thinking that could be observed during a lesson and to give them language to discuss the student thinking that was observed. She found that "discussions that were linked to the framework were more substantive" (p. 17) in that they were more analytical in nature and grounded in video evidence. In short, this research suggests that specific prompts and frameworks support the noticing of what is valued within classroom interactions in a given project. Our study builds on this work by examining the use of an explicit analytic framework to scaffold PTs' noticing of instances of student mathematical thinking that have significant potential to enhance the learning of important mathematics.

\section{Theoretical Framework}

The intervention in this study was grounded in a situated perspective (Borko, 2004), which supports the idea that learning should be embedded in activities that closely resemble the situations in which the learning will be applied. This understanding influenced the design of the intervention, in which videos from local teachers' classrooms - the same classrooms in which participants would later student teach — were positioned as objects of inquiry. In addition, the classroom videos were recorded from a front-of-classroom teacher's perspective to more closely situate participants' learning in the context of teaching.

Consistent with Jacobs and colleagues (2010), we aimed to promote the professional 
noticing of [students'] mathematical thinking. We follow their definition of this practice to include three interrelated skills: (a) attending to student thinking, (b) interpreting what students are saying mathematically, and (c) deciding how to respond. In this study, we focused only on the first two components of this practice because these are necessary first steps in learning to notice. Our choice to focus our work on the noticing of students' mathematical thinking stems from its close connection to our goal of helping prospective teachers learn to enact ambitious teaching (Lampert et al., 2010)—“deliberately responsive and discipline-connected instruction" (p.130) that supports all students in developing deep understanding of mathematics. Noticing is also identified by the NCTM (2014) as an element of effective teaching. In fact, they note that the practice of eliciting and using evidence of student thinking requires two component skills of noticing - identifying important elements of students' mathematical thinking and interpreting what they mean in relation to student learning.

Although our work is firmly grounded in the noticing of student mathematical thinking, we take the perspective that not all instances of such thinking have the same potential to enhance student learning. Thus, we focus specifically on noticing instances of student thinking that have significant potential to be used during the lesson to support the learning of important mathematics. In particular, we draw on the theoretical work of Authors (2015) that defined High Leverage Instances [HLIs] as occurring at the intersection of three characteristics: (a) student mathematical thinking, (b) significant mathematics, and (c) pedagogical opportunity. For each characteristic, two criteria were provided to determine whether an instance of student thinking embodies that characteristic. For student mathematical thinking the criteria are "(a) one can observe student action that provides sufficient evidence to make reasonable inferences about student mathematics and (b) one can articulate a mathematical idea that is closely related to the 
student mathematics of the instance — what we call a mathematical point” (pp. 93-94). The criteria for significant mathematics are "(a) the mathematical point is appropriate for the mathematical development level of the students and (b) the mathematical point is central to mathematical goals for their learning" (p. 97). Finally, "an instance embodies the pedagogical opportunity characteristic when (a) the expression of a students' mathematics creates an opening to build on student thinking to help develop an understanding of the mathematically significant point of the instance and (b) the timing is right to take advantage of the opening" (p. 103). When an instance of student thinking satisfies all six criteria, it embodies the three requisite characteristics and is a HLI. It is important to note that the HLI framework was developed to characterize instances of high-leverage student thinking in any classroom - regardless of factors such as grade level, mathematical content, or mode of instruction-so is robust enough to analyze a range of classroom video.

The study was also informed by Author's (2013) characterization of a high potential moment (HPM) — "an instance in a classroom lesson in which an interruption in the flow of the lesson provides the teacher an opportunity to modify instruction in order to extend or change the nature of students' mathematical understanding" (p. 127). By analyzing video of beginning teachers' practice, these researchers identified five types of HPMs that had high potential to support students' mathematical learning: extending, incorrect mathematics, sense-making, mathematical contradiction, and mathematical confusion. The finding that mathematical moments with potential to support students' mathematical understanding might fall into a small number of categories informed the initial learning-to-notice activities in this intervention. In particular, we have come to see HPMs as a subset of HLIs and conjectured that first focusing the PTs on noticing these general categories of important instances (HPMs) would scaffold them in 
honing in on potentially important moments that would warrant further analysis using the HLI framework.

\section{Methodology}

\section{Context}

The study participants were 17 prospective mathematics teachers (PTs) enrolled in an early field experience course at a Midwestern U.S. university between fall 2011 and fall 2014. This course is one of the first that PTs enroll in as part of their teacher preparation program, typically at the start of their third year of university study. In their first two years of study, prior to their admission to the teacher education program, the PTs had taken only general education courses and content courses in their major and minor focus areas, so they had little to no other teacher education experiences to draw upon during the field experience course. The PTs participated in the study in five cohorts, each with three or four members. The first author was the instructor of the course and facilitated all intervention activities.

\section{The Intervention}

Individual participant activities. In the modified field experience, each PT was assigned to observe one to two hours per week in a local secondary (U.S. grades 6-12) mathematics classroom. The teachers they observed all had more than 10 years of teaching experience. Participants recorded videos of mathematics lessons in these classrooms, one each week on a rotating basis, with each participant recording three or four lessons during the semester. Efforts were made to collect video from a range of mathematics courses (from middle school to calculus in some semesters) with lessons focused on varied mathematical topics. Because the PTs recorded in the classrooms in which they were observing, the videos that were used in the intervention each semester were generally not the same, but some videos were reused in different 
semesters when needed (due to, for example, technical difficulties or weather-based cancellations). The instructional portions of each classroom video were left mainly unedited for analysis. Editing occurred on portions of the video in which students could not easily be heard or in which the teacher was engaged in administrative tasks.

Each week, the PTs used the Studiocode (SportsTec, 1997-2016) video analysis software to individually analyze one common classroom video. This analysis included marking important instances they noticed in the video and providing written descriptions to give insight into their thinking about each instance. The PTs completed their analysis one to two days prior to a weekly meeting among the cohort members and the research team to allow the researchers time to review their analyses as part of the meeting preparation.

Researcher activities. Two or three research team members used Studiocode to code the same videos as the PTs. After coding individually, the team met to agree on instances that were HLIs in the videos. They then viewed the PTs' video coding, discussed the instances the PTs had identified as important, and decided which instances would be discussed at the weekly meeting. The instances selected for discussion were chosen based on ongoing analysis of the PTs' learning and varied across several factors, including instances that were coded by multiple PTs, by only one PT, and those that the researchers had identified as HLIs but the PTs had all missed; instances coded by multiple PTs for differing reasons; instances that were HLIs as well as those that did not meet one or more HLI criteria; and instances that were different types of HPMs. Sometimes several similar instances were selected for collective consideration to help the PTs learn to differentiate among instances that shared surface features, but varied in mathematical importance. 
Weekly meetings. Weekly meetings among the participants and the research team were modeled after a video club (e.g., Sherin \& van Es, 2009) and were facilitated by the first author, an experienced teacher educator. Other members of the research team attended the meetings to collect data and listen to the conversation to inform subsequent team discussions about the PTs' progress and learning needs. Five to eight video instances were typically discussed in each meeting to build PTs' skills in noticing mathematically important moments. For each instance, the facilitator usually played the instance and then prompted the PTs to discuss what might be important to notice and why. The facilitator frequently asked the PTs probing questions, focused them on particular HLI criteria, and encouraged them to respond to one another's ideas. Additional meeting activities are described in the following section.

Activities by cohort. Each cohort engaged in similar video analysis and meeting activities, although some modifications were made each semester based on what had been learned in previous iterations of the intervention (Table 1) and on the cohort's identified learning needs. In the description of the specific intervention activities that follows, an activity or scaffold that was introduced in the Week x meeting went into effect in the PTs' Week $(x+1)$ video analysis.

Table 1

Intervention Activities by Cohort

\begin{tabular}{|c|c|c|c|c|c|c|c|c|c|c|c|c|}
\hline & & \multicolumn{11}{|c|}{ Week } \\
\hline & & 1 & 2 & 3 & 4 & 5 & 6 & 7 & 8 & 9 & 10 & 11 \\
\hline \multirow{2}{*}{$\begin{array}{c}\text { Cohort } \\
1 \\
\end{array}$} & Labels & & & & $X$ & $X$ & $X$ & $X$ & $X$ & $\mathrm{X}$ & & \\
\hline & HLI (general) & & & & & $X$ & $X$ & $X$ & $X$ & $X$ & & \\
\hline \multirow{2}{*}{$\begin{array}{c}\text { Cohorts } \\
2-3\end{array}$} & Labels & & & & $X$ & $X$ & $X$ & $X$ & $X$ & $\mathrm{X}$ & $\mathrm{X}$ & \\
\hline & HLI (general) & & & & & & $X$ & $X$ & $X$ & $X$ & $X$ & \\
\hline \multirow{2}{*}{$\begin{array}{c}\text { Cohort } \\
4\end{array}$} & Labels & & & & $X$ & $X$ & $X$ & $\mathrm{X}$ & $X$ & $X$ & $X$ & \\
\hline & HLI (specific) & & & & & & $X$ & $X$ & $X$ & $X$ & $X$ & \\
\hline \multirow{2}{*}{$\begin{array}{c}\text { Cohort } \\
5\end{array}$} & HLI (specific) & & & $\mathrm{X}$ & $X$ & $X$ & $X$ & $X$ & $X$ & & $X$ & $\mathrm{X}$ \\
\hline & Math Point & & & & & & & & & $\mathrm{X}$ & & \\
\hline
\end{tabular}


At the start of the intervention, all the cohorts were asked to mark mathematically important moments a teacher should notice in the classroom. The definition of this construct was left open-ended to provide baseline data for PT noticing. The first four cohorts co-developed labels (e.g., student question, conceptual wrong answer, student realization, alternate right answer) in the Week 2 and Week 3 group meetings to describe and categorize types of mathematically important moments. The use of these labels was informed by Author's (2013) HPM types, but these categories were not made explicit to the PTs to provide them an opportunity to make sense of the types of instances that might be important to notice. Most of the labels developed by the PTs were similar to those in the HPM study and similar among the cohorts, but were named differently because they were in the PTs' own language. After agreeing on an initial set of labels at the end of the Week 3 meeting, the PTs in these four cohorts assigned those labels to important moments they identified in subsequent videos.

Each cohort was introduced to a variation of the HLI framework at some point during the semester: cohort 1 in Week 4, cohorts 2-4 in Week 5 and cohort 5 in Week 2. This framework evolved over the four years of the study, so the early cohorts (1-3) used a general version of the framework in which the HLI criteria were loosely defined in terms of student thinking, important mathematics, and pedagogical opportunity. Cohorts 4 and 5 used the most explicit, analytical version of the framework as described in Leatham et al. (2015). In the week immediately following the introduction of the framework, the PTs re-analyzed two videos to help them learn to apply the framework to instances that members of their cohort had previously identified as important. In subsequent weeks, the PTs were prompted to identify moments in the videos that were HLIs, as defined by the version of the framework available at the time. In the last two 
videos, cohort 5 was pushed to explicitly discuss each characteristic of the framework in their description of noticed instances by providing them a template that prompted them to explain how each of the six criteria of a HLI was met in each instance.

Cohort 5 did not use labels, but other foci were introduced throughout the semester. An activity was done during the Week 9 meeting to help them learn to identify the mathematical points of instances; the PTs were given proposed statements of mathematical points and were asked to decide as a group if they met the definition of mathematical point (Author, in press) and to rewrite those statements that did not qualify. This activity, as well as the template to guide PTs to analyze instances in relation to each characteristic of the HLI framework, were intended to prompt more refined analyses and descriptions.

\section{Data Collection and Analysis}

The data for the study were the PTs' individual video analyses — the instances they identified and their corresponding explanations - and video recordings of the weekly meetings. Two different analyses were conducted to determine how the PTs' noticing changed during the intervention: (a) characteristics of the PTs' noticing and (b) the extent to which the PTs' noticing aligned with the HLIs in the video. The unit of analysis for both was a PT-identified video instance.

Noticing characteristic analysis. Drawing on coding frameworks used in previous research (e.g., Author, 2008; van Es \& Sherin, 2008), the first analysis consisted of coding characteristics of each PT-identified instance, including who or what was the object of the PT noticing (agent) and the way in which the mathematics of an instance was discussed (specificity of mathematics). Instances coded with any student agent were assigned an additional code to describe the focus of the PT's noticing of the student(s)—what about the student(s) was attended 
to. A codebook (e.g., Ryan \& Bernard, 2000) was created that included definitions of each code and examples. The initial codes were drawn from previous work, but these codes were refined and additional codes were developed based on themes that emerged from the data, particularly for the focus characteristic. Thus, the codebook was continuously revisited and refined during the early phases of coding to develop a consensus meaning of each code among the members of the research team. Figure 1 gives the coding categories, descriptions, and codes.

[Insert Figure 1 about here]

To give a sense of some of the key codes that we will discuss, consider the nine instances in Figure 2. These provide contrasts between agents and specificity, and when applicable, the focus of noticing. First we examine the agents. Instance 1 was coded Mathematics $(\mathrm{M})$ because the importance of the mathematics was paramount rather than the people in the classroom. Instance 2 was coded Teacher $(\mathrm{T})$ because the teacher's actions were the implied object of noticing. Students were referenced in this instance, but the PT did not notice the students' activity; the PT assumed the students understood because the teacher explained the concept. Instances 3, 5, and 7 concentrated on both student and teacher actions. Instances 3 and 5 were coded Teacher/Student (T/S) because greater emphasis was placed on the teacher's actions (getting the class engaged, guiding and asking the right questions), whereas instance 7 was coded Student/Teacher $(\mathrm{S} / \mathrm{T})$ because the student's realization received more emphasis than the teacher's actions. Instance 4 was coded Student Group $(\mathrm{Sg})$ because the explanation made a generalization about the class as a whole. Instances 6, 8, and 9 were coded Individual Student (Si) because a particular student's mathematical question or statement was the object of noticing. [Insert Figure 2 about here] 
Next, we examine the specificity of mathematics. Instance 3 was coded Non-math (NM) because the PT described student involvement instead of student mathematical thinking. The text for this instance could easily describe a portion of a history class; nothing ties it to mathematical content. Instances 1 and 6 were coded General Math (GM) because they referenced the classroom mathematics in a general, overarching sense or pointed to an event such as a mathematical student question but provided no details about the mathematics. The remaining instances were coded Specific Math (SM) because the PT referenced a specific mathematical concept or process.

When the student was included in the agent, we examined the focus of the noticingwhat about the student was noticed. Instances 1 and 2 did not have a student agent, so did not receive a focus code. Instances 3 and 5 focused on interactions between students and the teacher. Instance 3 was focused on classroom management and how students felt so it was coded Affective Interaction (AI); instance 5 examined how the students worked with each other and with the teacher to learn mathematics so it was coded Mathematical Interaction (MI). In instance 4, a claim was made about what the whole class understood, in this case, based on an answer given as a general acclamation by the class. This instance was coded General Understanding (GU) because the claim was an inference about what the entire class comprehended. Instances 6 and 7 were coded Noting Student Mathematics (NSM) because a specific student action or piece of student work was described. Instances 8 and 9 were coded Analyzing Student Mathematics (ASM) because the PT went beyond simply stating what a student did to reason about why, in these instances, the student made the error that occurred or asked a question about the difference between examples. 
In the analysis process, two or three researchers first individually coded each PTidentified instance $(n=553)$ for each of the three characteristics. The researchers then met to compare and reconcile the coding. Instances for which the researchers disagreed about one or more codes were discussed until agreement was reached; in the case where two researchers were involved in the initial coding, a third researcher was brought into the discussion to reach consensus when needed. Due to the amount of interpretation necessary to make sense of what were sometimes brief statements provided by the PTs, several precautions were taken to ensure consistent and reliable coding. First, multiple coders were used through the entire coding process. Second, all available data were considered when assigning a code to the PTs' noticing. In this process, a PT's written description of an instance received the most weight. When available, a PT's label and what (s)he said about the instance in the weekly meeting were considered. Meeting comments received more weight if the PT was the first to speak about an instance due to the possibility that their thinking could be altered by other PTs' comments about an instance. Subsequent PT statements were considered only when it was clear that the comments were consistent with the original description in the PT's video analysis.

After each instance was coded for the components of noticing, the analysis focused on comparing this coding at the beginning and end of the intervention. We also examined instances that were coded as exhibiting all of our noticing targets — individual student as agent, specific mathematics for specificity, and noting or analyzing student mathematics for focus- to understand the extent to which the PTs were able to engage in all of these simultaneously. We considered this our target for noticing because it is these components that constitute the skills of professional noticing of student thinking: attending to the specifics of the mathematics students 
express and interpreting what it means in terms of the students' mathematical understanding (Jacobs et al., 2010).

HLI analysis. The second analysis focused on whether the instances the PTs coded aligned with the HLIs in the classroom video and, if so, whether their description of the instance was consistent with the reasons the research team had identified it as a HLI. Because the research team was experienced with using the HLI framework, the instances they agreed were HLIs were considered the set of instances that satisfied the HLI criteria. Each instance identified by a PT was first coded by one researcher as either a HLI or a non-HLI based on its timewise alignment (or lack thereof) with a HLI in the video. Then the PT's reasoning about each HLI was classified as either consistent or inconsistent based on the previously-assigned agent and topic codes, in particular, whether the description of the instance focused on students' mathematical thinking. When necessary, instances were discussed with another researcher until agreement about the instance consistency was reached. All of the HLI coding was verified by a second researcher.

In both a consistent HLI and an inconsistent HLI, the instance the PT noticed occurred at the same time as a HLI in the video. In a consistent HLI, the PT's focus and reasoning were on the student mathematical thinking that made the instance a HLI. Instance 8 in Figure 2 is an example of such an instance. This instance was a HLI because the student's statement that the absolute value of negative five is five "because it's just the opposite" indicated a common misconception; this was the same mathematics identified by the PT. In an inconsistent HLI, the PT's focus was on an instance associated with a HLI, but was not on the student mathematical thinking itself. For example, in instance 5, the PT focused on the teacher's response-_"guiding them and asking the right questions to help initiate answers"-rather than on the mathematics that underlies the student's statement that "you move the decimal two times to the left" when 
converting from a percentage to a decimal representation. Other inconsistent HLIs focused on the general mathematical significance of an instance or a student's self-confidence as they offered a response. In a non-HLI, the PT either (a) noticed an instance of student mathematical thinking that met some, but not all, of the HLI criteria or (b) was focused on something that was not consistent with the HLI criteria. Instance 4 is an example of the former because the PT noticed an instance of student mathematical thinking that did not produce an opening to discuss the students' mathematics; students agreed that the teacher's ordering of the numbers was incorrect, indicating they already understood how to compare decimal numbers. Instances 1, 2, and 3 are examples of the latter because the focus is not on a student. After each PT-identified instance was coded, the analysis focused on comparing the PTs' noticing of HLIs at the beginning and end of the intervention.

\section{Results}

The goal of the intervention was to promote the noticing of instances of student mathematical thinking that have significant potential to be capitalized on during a lesson to support student learning. Thus, we focus on the extent to which we were able to promote such noticing. In the discussion of our results, initial refers to the PTs' noticing in the first two videos each semester, before there was any attempt to influence their noticing by introducing labels or the framework. Final refers to the PTs' noticing in the last four videos each semester — an indication of the PTs' most refined noticing, after all five cohorts were supported by the HLI framework. We use four videos to report the final noticing because most of the PTs noticed substantially fewer instances in these later videos. In fact, PTs noticed an average of 8.8 instances per video in the initial videos, and less than half that number (3.75 instances/video) in the final four videos, an indication that they were becoming more selective about the instances 
they deemed important to notice. To support comparison among the cohorts, we report the data in the following sections as percentages of the total number of instances analyzed. To allow the reader to make meaning of those percentages, Table 2 summarizes the data that were analyzed. Table 2

Summary of coded instances by data set.

\begin{tabular}{llccccc}
\hline & & Cohort 1 & Cohort 2 & Cohort 3 & Cohort 4 & Cohort 5 \\
\hline Number of Participants & & 4 & 3 & 3 & 4 & 3 \\
\hline Total Number of Instances & Initial & 40 & 28 & 47 & 96 & 88 \\
& Final & 61 & 30 & 50 & 58 & 55 \\
\hline Average Instances per & Initial & 10 & 9.3 & 15.7 & 24 & 29.3 \\
Participant in Data Set & Final & 15.3 & 10 & 16.7 & 14.5 & 18.3 \\
\hline Range of Instances per & Initial & $8-15$ & $8-11$ & $15-17$ & $16-38$ & $18-35$ \\
Participant in Data Set & Final & $13-17$ & $6-15$ & $13-21$ & $11-17$ & $17-20$ \\
\hline
\end{tabular}

\section{Noticing Characteristic Analysis}

The first analysis focused on analyzing characteristics of the instances the PTs noticed in the classroom video. We first discuss the individual characteristics of the PTs' noticing — agent, specificity, and focus. We then discuss instances in which the characteristics that align with our goals were present simultaneously, in what we call target noticing.

Agent. Table 3 shows the average percentage of instances noticed by the PTs in each cohort that focused primarily on students, on the teacher, and on the mathematics itself (independent of the students or teacher) in the initial and final data, as well as the percentage of instances they noticed that were coded in each distinct agent category. At the start of the intervention, a large percentage of the PTs' noticing was focused primarily on the teacher in the video, and to a lesser extent, on the mathematics itself. This non-student focused noticing accounted for between $28 \%$ (cohort 1) and $79 \%$ (cohort 4) of the initial noticing. With the exception of cohort 1, half or fewer of the instances noticed by the PTs in the initial data had a 
primary student focus. At the end of the intervention, however, the majority of each cohort's noticing — ranging from $86 \%$ to $100 \%$ of the instances - was focused on the students in the video.

Table 3

Participant Noticing by Agent

\begin{tabular}{ccccccc}
\hline \multirow{2}{*}{ Primary Student } & & Cohort 1 & Cohort 2 & Cohort 3 & Cohort 4 & Cohort 5 \\
& Initial & $72 \%$ & $45 \%$ & $50 \%$ & $21 \%$ & $26 \%$ \\
& Final & $89 \%$ & $100 \%$ & $89 \%$ & $99 \%$ & $86 \%$ \\
\hline \multirow{2}{*}{ Individual Student } & Initial & $29 \%$ & $9 \%$ & $8 \%$ & $8 \%$ & $1 \%$ \\
& Final & $34 \%$ & $86 \%$ & $73 \%$ & $75 \%$ & $73 \%$ \\
\hline \multirow{2}{*}{ Student Group } & Initial & $36 \%$ & $25 \%$ & $22 \%$ & $2 \%$ & $17 \%$ \\
& Final & $7 \%$ & $14 \%$ & $11 \%$ & $6 \%$ & $7 \%$ \\
\hline \multirow{2}{*}{ Student/Teacher } & Initial & $7 \%$ & $10 \%$ & $20 \%$ & $11 \%$ & $8 \%$ \\
& Final & $48 \%$ & $0 \%$ & $5 \%$ & $17 \%$ & $5 \%$ \\
\hline \multirow{2}{*}{ Primary Teacher } & Initial & $25 \%$ & $33 \%$ & $43 \%$ & $63 \%$ & $60 \%$ \\
& Final & $9 \%$ & $0 \%$ & $8 \%$ & $1 \%$ & $14 \%$ \\
\hline \multirow{2}{*}{ Teacher/Student } & Initial & $11 \%$ & $13 \%$ & $14 \%$ & $12 \%$ & $23 \%$ \\
& Final & $6 \%$ & $0 \%$ & $8 \%$ & $1 \%$ & $13 \%$ \\
\hline \multirow{2}{*}{ Teacher } & Initial & $14 \%$ & $20 \%$ & $29 \%$ & $52 \%$ & $38 \%$ \\
& Final & $3 \%$ & $0 \%$ & $0 \%$ & $0 \%$ & $2 \%$ \\
\hline \multirow{2}{*}{ Math } & Initial & $3 \%$ & $22 \%$ & $6 \%$ & $16 \%$ & $14 \%$ \\
& Final & $1 \%$ & $0 \%$ & $3 \%$ & $0 \%$ & $0 \%$ \\
\hline
\end{tabular}

We were particularly interested in the extent to which PTs focused on individual students because this agent aligned with our noticing goal. Initially, none of the cohorts' student-directed noticing was focused mainly on individual students, with the highest percentage displayed by cohort $1(29 \%)$. With the exception of cohort 1 , however, the PTs' final noticing was primarily focused on individual students $(73 \%$ to $86 \%$ of all instances, and $76 \%$ to $86 \%$ of the primary student instances), indicating that the intervention was successful in focusing the PTs on what individual students were saying or doing during the lesson — a focus consistent with the attending aspect of noticing students' mathematical thinking. 
Specificity of mathematics. The specificity of the PTs' noticing indicates whether and in what level of detail the mathematics in an instance was discussed. As seen in Table 4, nonmathematical noticing was initially present for all cohorts and was most prevalent for cohort 5 $(35 \%)$. All of the cohorts discussed the mathematics in a specific way more than the other categories in the initial data (between $38 \%$ and $74 \%$ of instances in initial data), although cohort 5's noticing was fairly equally distributed between non-mathematical, general mathematical and specific mathematical noticing. In the final data, no non-mathematical noticing was present. In fact, all of the cohorts became more specific in their discussion of the mathematics throughout the intervention, with cohort 5 showing the most substantial change in specificity.

Table 4

Specificity of Participant Noticing

\begin{tabular}{llccccc}
\hline & & Cohort 1 & Cohort 2 & Cohort 3 & Cohort 4 & Cohort 5 \\
\hline \multirow{2}{*}{ Non-math } & Initial & $17 \%$ & $10 \%$ & $2 \%$ & $4 \%$ & $35 \%$ \\
& Final & $0 \%$ & $0 \%$ & $0 \%$ & $0 \%$ & $0 \%$ \\
\hline \multirow{2}{*}{ General Math } & Initial & $35 \%$ & $16 \%$ & $39 \%$ & $24 \%$ & $27 \%$ \\
& Final & $24 \%$ & $19 \%$ & $13 \%$ & $12 \%$ & $6 \%$ \\
\hline \multirow{2}{*}{ Specific Math } & Initial & $48 \%$ & $74 \%$ & $59 \%$ & $72 \%$ & $38 \%$ \\
& Final & $76 \%$ & $81 \%$ & $87 \%$ & $88 \%$ & $94 \%$ \\
\hline
\end{tabular}

Focus of noticing. Instances with any student agent $(\mathrm{Si}, \mathrm{Sg}, \mathrm{S} / \mathrm{T}$ or $\mathrm{T} / \mathrm{S})$ were coded to characterize what about the students the PTs had noticed. As a reminder, the goal was to focus the PTs' attention on what students were saying mathematically, so the target was noting or analyzing the student mathematics, with "analyzing" deemed more desirable than "noting" because analyzing provided evidence of the PTs engaging in the interpreting aspect of noticing.

As can be seen in Table 5, there was some noticing of affective interactions in the initial data, especially for cohorts 2 and 5, but this focus was completely eliminated by the end of the intervention. Each cohort also decreased in their noticing of mathematical interactions. 
Interestingly, $74 \%$ of cohort 5's initial noticing was focused on describing classroom interactions rather than on student mathematical thinking. Their final noticing of such interactions decreased to only $11 \%$ of instances, the most substantial change of any cohort. The focus on making unsubstantiated claims about students' general understanding of the mathematics was also present for all cohorts in the initial data. The change in this noticing focus was mixed among the cohorts, with the first two cohorts showing a small increase in their focus on general understanding, and the last three cohorts decreasing in this focus. In fact, the last cohort had no instances coded as general understanding in the final data.

Table 5

Participant Noticing Focus in Instances with Student Included in Agent

\begin{tabular}{llccccc}
\hline & & Cohort 1 & Cohort 2 & Cohort 3 & Cohort 4 & Cohort 5 \\
\hline Affective & Initial & $14 \%$ & $41 \%$ & $5 \%$ & $3 \%$ & $31 \%$ \\
Interaction & Final & $0 \%$ & $0 \%$ & $0 \%$ & $0 \%$ & $0 \%$ \\
\hline Mathematical & Initial & $15 \%$ & $4 \%$ & $13 \%$ & $9 \%$ & $43 \%$ \\
Interaction & Final & $10 \%$ & $0 \%$ & $5 \%$ & $1 \%$ & $11 \%$ \\
\hline General & Initial & $21 \%$ & $4 \%$ & $53 \%$ & $36 \%$ & $20 \%$ \\
Understanding & Final & $28 \%$ & $6 \%$ & $8 \%$ & $1 \%$ & $0 \%$ \\
\hline Noting Student & Initial & $53 \%$ & $35 \%$ & $29 \%$ & $52 \%$ & $7 \%$ \\
Mathematics & Final & $61 \%$ & $70 \%$ & $80 \%$ & $88 \%$ & $48 \%$ \\
\hline Analyzing Student & Initial & $0 \%$ & $17 \%$ & $0 \%$ & $0 \%$ & $0 \%$ \\
Mathematics & Final & $1 \%$ & $24 \%$ & $7 \%$ & $9 \%$ & $38 \%$ \\
\hline
\end{tabular}

Looking at noting and analyzing student mathematics collectively-the two categories consistent with our target of noticing students' mathematical thinking — one can see that there was a wide variation among the cohorts in the initial data. Table 5 shows that cohorts 1,2 , and 4 had $53 \%, 52 \%(35 \%+17 \%)$ and 52\%, respectively, of instances coded with one of these foci, while cohorts 3 and 5 had considerably lower percentages (29\% and 7\%, respectively). In the initial data, only cohort 2 demonstrated any analyzing, all attributable to just one PT. Each cohort 
increased their noticing with these two foci. In fact, with the exception of cohort 1, the final data shows that $86 \%$ or more of the PTs' student-centered noticing was coded as noting or analyzing student mathematics, with noting instances accounting for the majority of the instances for cohorts 2, 3 and 4, and a more even split between noting and analyzing (48\% and 38\%, respectively) for cohort 5 . Cohorts 2 and 5 demonstrated the highest percentage of analyzing, but as in the initial data, cohort 2's analyzing was largely attributable to one PT. Cohort 5's percentage of analyzing was not only the highest among all cohorts, but was also more consistent among the PTs in the cohort. Collectively, the data suggests that the intervention was successful not only in focusing the PTs' attention on students, but also on noting and analyzing the important mathematical thinking that these students produced during the classroom lessons.

Target noticing. A goal of the intervention was to improve PTs' ability to notice and reason about instances in a defined way—-focusing on an individual student agent, discussing the mathematics in a specific manner, and noting or analyzing the student mathematics. Thus, we were interested in the PT-identified instances that included all of the target behaviors previously analyzed, which we refer to as target noticing. In Table 6, broad target indicates instances that were focused on individual students, specific mathematics, and had either a noting or analyzing student mathematics focus. Narrow target includes the same two first components, with only analyzing as the focus. As seen in the table, all cohorts demonstrated an increase in broad target noticing with initial percentages ranging from $0 \%$ to $14 \%$ of instances and final percentages ranging from $21 \%$ to $70 \%$ of instances. Cohorts $2-5$ all showed substantive growth in their broad target noticing, with cohort 5 displaying both the largest increase in and the highest final percentage of such noticing. It is also interesting to note that the final percentages of broad target 
noticing generally increased from one cohort to the next, a potential indicator that the intervention improved with each iteration.

Table 6

Participant Target Noticing

\begin{tabular}{llccccc}
\hline & & Cohort 1 & Cohort 2 & Cohort 3 & Cohort 4 & Cohort 5 \\
\hline \multirow{2}{*}{ Broad Target } & Initial & $14 \%$ & $10 \%$ & $2 \%$ & $6 \%$ & $0 \%$ \\
& Final & $21 \%$ & $60 \%$ & $67 \%$ & $68 \%$ & $70 \%$ \\
\hline \multirow{2}{*}{ Narrow Target } & Initial & $0 \%$ & $4 \%$ & $0 \%$ & $0 \%$ & $0 \%$ \\
& Final & $0 \%$ & $15 \%$ & $7 \%$ & $9 \%$ & $33 \%$ \\
\hline
\end{tabular}

The narrow target noticing data paints a different picture of the gains that were made.

Cohort 1 displayed no narrow target noticing, either in the initial or final data. Cohorts 2, 3 and 4 made some gains, but still displayed little narrow target noticing at the end. This is not surprising given that these cohorts displayed a low percentage of analyzing student mathematics, one of the necessary components of narrow target noticing. Only cohort 5 made substantial gains in this more specific type of noticing, engaging in narrow target noticing in one-third of instances in the final data. This cohort was also the one that engaged in analyzing student mathematics in the highest percentage of instances, 38\%. Thus, the intervention was more effective in promoting analyzing student mathematics and thus narrow target noticing for this cohort.

\section{HLI Analysis}

An additional measure of PT learning was whether they became better able to identify instances of student mathematical thinking that had potential to be built upon by the teacher to support student learning of mathematics - that is, instances that were HLIs. Although there is overlap between these instances and those identified as target noticing, the analysis of the noticing of HLIs tells us whether the PTs were noticing these particularly high-leverage instances of student thinking, whereas the target instance analysis gives an indication of whether 
PTs were noticing individual students' mathematical thinking and reasoning about it in a specific manner.

Table 7 gives the percentage of the instances PTs noticed that coincided with instances that were HLIs, with either consistent or inconsistent reasoning (Coincide with HLIs), as well as the percentage of instances that were consistent HLIs. All of the cohorts increased in the percentage of the instances they noticed that were HLIs, with between $63 \%$ and $82 \%$ of the PTs' identified instances coinciding with HLIs in the final data. Although not all of these instances directly addressed the mathematical importance of the HLI, there was an indication that the PTs at least noticed that something noteworthy had happened in the video, even if it was a teacher's response or a different piece of student mathematical thinking.

Table 7

Participants' Noticing of HLIs

\begin{tabular}{clccccc}
\hline & & Cohort 1 & Cohort 2 & Cohort 3 & Cohort 4 & Cohort 5 \\
\hline Coincide & Initial & $46 \%$ & $33 \%$ & $43 \%$ & $31 \%$ & $23 \%$ \\
with HLIs & Final & $82 \%$ & $72 \%$ & $64 \%$ & $63 \%$ & $82 \%$ \\
\hline Consistent & Initial & $35 \%$ & $20 \%$ & $27 \%$ & $8 \%$ & $2 \%$ \\
HLIs & Final & $79 \%$ & $72 \%$ & $59 \%$ & $61 \%$ & $74 \%$ \\
\hline
\end{tabular}

The consistent HLI data indicates that the PTs became more adept at identifying instances that met all the HLI criteria, with between $59 \%$ and $79 \%$ of PT-identified instances showing this consistency in the final data. This is a potential measure of noticing expertise. Additionally, since consistent HLIs are a subset of instances that coincide with HLIs, the very similar final percentages indicate that the number of inconsistent HLIs was minimal in the final data.

We were also interested in the proportion of all of the HLIs in the video that were noticed by PTs, both for any reasoning (Coincide with HLIs in Table 8) and for consistent reasoning. In 
cohorts 2-4, the percentage of all HLIs in the video that were coded by PTs actually decreased from the initial to final data. This is not completely surprising considering that the PTs chose considerably fewer instances overall in the final videos. The percentage of HLIs that the PTs noticed for reasons consistent with what made them HLIs increased in all cohorts, although not to the extent that we had hoped. Even in the best cases, the PTs noticed only about a third of the HLIs in the video.

Table 8

Percentage of Total HLIs Identified by Participants

\begin{tabular}{clccccc}
\hline & & Cohort 1 & Cohort 2 & Cohort 3 & Cohort 4 & Cohort 5 \\
\hline Coincide & Initial & $30 \%$ & $28 \%$ & $28 \%$ & $45 \%$ & $30 \%$ \\
with HLIs & Final & $36 \%$ & $16 \%$ & $21 \%$ & $33 \%$ & $41 \%$ \\
\hline Consistent & Initial & $23 \%$ & $17 \%$ & $17 \%$ & $12 \%$ & $2 \%$ \\
HLIs & Final & $35 \%$ & $18 \%$ & $20 \%$ & $32 \%$ & $37 \%$ \\
\hline
\end{tabular}

\section{Discussion and Conclusions}

The goal of the intervention in this study was to scaffold PTs' noticing of instances of student mathematical thinking that have significant potential to be used during a lesson to support students' mathematical learning. Here we consider several ways the results indicate that the intervention was successful in accomplishing this goal.

The data showed that the intervention developed PTs' ability to notice aspects of classroom interactions that comprised subcomponents of our noticing goal. From the beginning to the end of the intervention, all of the cohorts increased in the percentage of instances in which students were the primary agent, with corresponding decreases in their noticing of the teacher or the mathematics independent of the students. With the exception of cohort 1 , the majority of the PTs' noticing became directed at individual students. They also developed an ability to attend to the specific mathematics in an instance, rather than discussing the mathematics in only a general 
way or not at all. Their noticing focus shifted away from classroom interactions, and turned toward noting and, in the case of cohorts 2 and 5, analyzing students' mathematics.

Our target noticing analysis showed changes in the extent to which the PTs were able to engage in all the subcomponent skills of our noticing goal within a single instance, what we see as comparable to the focused level of noticing defined by van Es (2011). Broad target noticingwhich included individual students, specific mathematics, and noting or analyzing student mathematics - increased for all the cohorts, although it remained relatively low for cohort 1 . The intervention was not as successful, however, at developing narrow target noticing, since only the last cohort was found to engage in such noticing a non-trivial percentage of the time $(33 \%$ of instances). Given Jacobs, Lamb, Philipp, and Schappelle's (2011) cross-sectional comparison of noticing based on teacher experience that led them to conclude that "expertise in professional noticing...is complex" and "may require years to develop" (p. 196), this finding is perhaps not surprising; it does, however, raise questions about whether aspects of the intervention might be modified to better develop the PTs' target noticing, or whether more time is simply needed to develop skill in such noticing.

Because we used the HLI framework to scaffold noticing, we were also able to document changes in the noticing of particular instances of student mathematical thinking - those that have significant potential to be used during a lesson to support mathematical understanding. This noticing analysis goes beyond many analyses that have previously been described in the literature in that it not only focuses on whether PTs attended to and interpreted students' mathematical thinking, but whether they were attending to and interpreting particular highleverage instances of student mathematical thinking. In other words, it places value on the particular instances that are noticed. Our data showed substantial increases in the percentage of 
instances noticed by the PTs that coincided with HLIs in the video and also in those that were HLIs with consistent reasoning, with between $59 \%$ and $79 \%$ of instances in the final data falling into this latter category. Like other studies (e.g., Sherin \& van Es, 2005), this finding indicates that the PTs were becoming more discriminating in their noticing. The percentage of HLIs that were noticed by the participants was lower, however, with the best cohorts noticing only $32 \%$ and $37 \%$ of HLIs in the videos. Together this data suggests that the PTs were becoming better able to narrow their noticing to instances that were HLIs, but were unable to identify all of the HLIs that occurred in the video. This is perhaps an indication that they became too discriminating in their noticing, which may signal that additional work is required to broaden their noticing to recognize a range of HLIs, including those that may be more subtle and thus more difficult to notice (e.g., those in which the mathematical issues are not obvious, or when multiple HLIs occur in quick succession; see Author, in press). In other words, it may be that for teachers to learn to notice particular instances of student mathematical thinking that align with the noticing goal of a teacher educator or researcher, their noticing may first have to be narrowed to focus on the specific mathematics students are discussing, and then be broadened again to allow them to see all of the potentially rich mathematical instances that come from students, not only those instances that are most obvious. Developing mathematical knowledge for teaching (Ball, Thames, \& Phelps, 2008) may be a critical part of this broadening, since such knowledge is essential for recognizing the mathematical significance of HLIs.

The findings of this study add support to a growing body of research demonstrating that it is feasible to develop PTs' professional noticing skills. Although we acknowledge that the small number of participants in each cohort is a limitation of the study, the fact that the general findings were replicated across five semesters lends support to the credibility of the results we 
have reported. In contrast to other studies that have worked with PTs later in their program of study (i.e., pedagogy courses or student teaching), we developed PTs' noticing skills at the start of a teacher preparation program, when the PTs had very little knowledge of students to draw upon. This suggests that it is possible to develop noticing as a foundational skill in a teacher education program — a skill that could support generative growth (Franke \& Kazemi, 2001) in subsequent coursework and field experiences as PTs engage in their own interactions with students around the students' mathematical ideas. Other key differences between this and many other interventions are that the noticing intervention used longer unedited classroom video recorded in local teachers' classrooms and focused on a range of mathematical topics. Thus, our findings suggest that it may not be necessary to narrow either the scope or length of classroom artifacts used to develop noticing skills (i.e., use short transcripts or video clips), nor to narrow the mathematical focus of the noticing activities.

Although the data should be interpreted with some caution due to the small cohort sizes, differences found among the cohorts suggest that the more specific versions of the HLI framework used with the latter cohorts may have been more effective in supporting many aspects of noticing. The first cohort, which used the least refined version of the framework, had the lowest percentages of instances that included many key aspects of our noticing goal, including individual students, specific mathematics, and broad target noticing. Their noticing of HLIs was comparable to that of cohorts 4 and 5-two of the cohorts that noticed the highest percentage of HLIs in the videos - but they did not reason about the instances as well as the later cohorts. The data showed a general trend that when a more explicit analytic framework was provided, the PTs learned to discuss the mathematics in a more specific way, and more often noted and analyzed what the students in the video were saying mathematically, resulting in a higher percentage of 
broad target noticing. Building on the findings and recommendations of others (e.g., Mitchell \& Marin, 2015; Roth McDuffie et al., 2014; Vondrová \& Žalská, 2015), we conjecture that using a framework to scaffold noticing results in more refined noticing. The data in this study suggested that using even a relatively loosely defined framework supported PT noticing, but using a more structured framework improved the outcomes of the noticing intervention by providing them with "categories and words with which to situate and discuss the thinking they noticed" (Walkoe, 2015, p. 22). Furthermore, the data suggested that using the detailed HLI framework in a highly specified way (i.e., using prompts focused on each HLI criterion) was the most effective in supporting more refined noticing.

While the findings that the intervention was successful in promoting the participants' noticing skills are noteworthy and an important first step in understanding the effects of the intervention, there are several open questions that we are working to address in subsequent analyses of our data. Importantly, we are now focused on understanding how individual PT's noticing skills developed and how their noticing contributed to the cohort results reported within. We are particularly interested in adding to the field's limited understanding of how PTs' interactions with their peers and the facilitator, as well as particular aspects of the intervention, supported the development of their noticing skills (Anthony et al., 2015). Additionally, the data reported here does not provide a clear picture of the specific ways in which the different versions of the framework supported PT noticing. Thus, more detailed qualitative comparisons among the cohorts are required to make sense of the nuances of the relationship between the nature and specificity of the framework and the PTs' learning to notice. We are also examining the PTs' proposed teacher responses to identified moments - the deciding how to respond component of professional noticing (Jacobs et al., 2010). Finally, ongoing work is focused on understanding 
how the noticing skills developed during this intervention transfer to noticing student ideas during the PTs' own instruction.

Beyond our own ongoing analyses, the results raise several other interesting questions for the field. Although our results suggest that noticing skills can be developed early in a teacher education program, we do not know how differences in the sequencing of noticing interventions with other elements of teacher preparation might affect how PTs draw on their noticing skills as beginning teachers. The target noticing and HLI noticing data also raise questions related to the optimal length of a noticing intervention-how much time is sufficient to narrow teacher noticing to a particular object of interest, while also broadening it to include all occurrences of that object, even those that are subtle? Because we see noticing as a high-leverage practice (Ball \& Forzani, 2009) for instruction that builds on student thinking, better understanding the development of teacher noticing holds potential for helping novice and experienced teachers alike learn to enact the type of instruction the field has been striving to achieve (e.g., Anthony et al., 2015; NCTM, 1989, 2014).

\section{References}

Anthony, G., Hunter, J., \& Hunter, R. (2015). Supporting prospective teachers to notice students’ mathematical thinking through rehearsal activities. Mathematics Teacher Education and Development, $17(2), 7-24$.

Ball, D. L., \& Forzani, F. M. (2009). The work of teaching and the challenge for teacher education. Journal of Teacher Education, 60(5), 497-511. doi:

$10.1177 / 0022487109348479$ 
Ball, D. L., Thames, M. H., \& Phelps, G. (2008). Content knowledge for teaching: What makes it special? Journal of Teacher Education, 59(5), 389-407. doi:

$10.1177 / 0022487108324554$

Barnhart, T., \& van Es, E. (2015). Studying teacher noticing: Examining the relationship among pre-service science teachers' ability to attend, analyze and respond to student thinking. Teaching and Teacher Education, 45, 83-93. doi: 10.1016/j.tate.2014.09.005

Berliner, D. C. (2001). Learning about and learning from expert teachers. International Journal of Educational Research, 35(5), 463-482. doi: 10.1016/S0883-0355(02)00004-6

Borko, H. (2004). Professional development and teacher learning: Mapping the terrain. Educational Researcher, 33(8), 3-15.

Fennema, E., Carpenter, T. P., Franke, M. L., Levi, L., Jacobs, V. R., \& Empson, S. B. (1996). Mathematics instruction and teachers' beliefs: A longitudinal study of using children's thinking. Journal for Research in Mathematics Education, 27, 403-434.

Fernández, C., Llinares, S., \& Valls, J. (2013). Primary school teacher's noticing of students' mathematical thinking in problem solving. The Mathematics Enthusiast, (10)1and2, 441468.

Franke, M. L., \& Kazemi, E. (2001). Learning to teach mathematics: Focus on student thinking. Theory into Practice, 40(2), 102-109.

Grossman, P. \& McDonald, M. (2008). Back to the future: Directions for research in teaching and teacher education. American Educational Research Journal, 45(1), 184-205. doi: $10.3102 / 0002831207312906$

Haltiwanger, L. \& Simpson, A. (2014). Secondary mathematics preservice teachers' noticing of students' mathematical thinking. In G. T. Matney \& S. M. Che (Eds.), Proceedings of the 
$41^{\text {st }}$ annual meeting of the Research Council on Mathematics Learning (pp. 49-56). San Antonio, TX.

Hill, H. C., Blunk, M. L., Charalambous, C. Y., Lewis, J. M., Phelps, G. C., Sleep, L., \& Ball, D. L. (2008). Mathematical knowledge for teaching and the mathematical quality of instruction: An exploratory study. Cognition and Instruction, 26(4), 430-511. doi: $10.1080 / 07370000802177235$

Jacobs, V. R., Lamb, L. L. C., \& Philipp, R. A. (2010). Professional noticing of children's mathematical thinking. Journal for Research in Mathematics Education, 41(2), 169-202.

Jacobs, V. R., Lamb, L. L.C., Philipp, R. A., \& Schappelle, B. P. (2011). Deciding how to respond on the basis of children's understandings. In M. G. Sherin, V. R. Jacobs, \& R. A. Philipp, (Eds.), Mathematics Teacher Noticing: Seeing through Teachers' Eyes (pp. 97116). New York: Routledge.

Jaworski, B. (1994). Investigating mathematics teaching: A constructivist enquiry. London: Routledge Falmer.

Lampert, M., Beasley, H., Ghousseini, H., Kazemi, E., \& Franke, M. (2010). Using designed instructional activities to enable novices to manage ambitious mathematics teaching. In M. K. Stein \& L. Kucan (Eds.), Instructional Explanations in the Disciplines (pp.129141). New York: Springer.

Leatham, K. R., \& Peterson, B. E. (2010). Secondary mathematics cooperating teachers' perceptions of the purpose of student teaching. Journal of Mathematics Teacher Education, 13(2), 99-119. doi: 10.1007/s10857-009-9125-0 
Masingila, J. O., \& Doerr, H. M. (2002). Understanding pre-service teachers' emerging practices through their analyses of a multimedia case study of practice. Journal of Mathematics Teacher Education, 5(3), 235-263. doi: 10.1023/A:1019847825912

Mitchell, R. N., \& Marin, K. A. (2015). Examining the use of a structured analysis framework to support prospective teacher noticing. Journal of Mathematics Teacher Education, 18(6), 551-575. doi: 10.1007/s10857-014-9294-3.

National Council of Teachers of Mathematics (1989). Curriculum and evaluation standards for school mathematics. Reston, VA: Author.

National Council of Teachers of Mathematics (2014). Principles to actions: Ensuring mathematical success for all. Reston, VA: Author.

Philipp, R. A., Ambrose, R., Lamb, L. L., Sowder, J. T., Schappelle, B. P., Sowder, L., ... \& Chauvot, J. (2007). Effects of early field experiences on the mathematical content knowledge and beliefs of prospective elementary school teachers: An experimental study. Journal for Research in Mathematics Education, 38(5), 438-476.

Ryan, G. W., \& Bernard, H. R. (2000). Data management and analysis methods. In N. K. Denzin \& Y. S. Lincoln (Eds.), Handbook of Qualitative Research Methods, Second Edition (pp. 769-802). Thousand Oaks, CA: Sage Publications.

Roth McDuffie, A., Foote, M. Q., Bolson, C., Turner, E. E., Aguirre, J. M., Bartell, T. G., Drake, C., \& Land, T. (2014). Using video analysis to support prospective K-8 teachers' noticing of students' multiple mathematical knowledge bases. Journal of Mathematics Teacher Education, 17, 245-270. doi: 10.1007/s10857-013-9257-0 
Santagata, R. (2011). From teacher noticing to a framework for analyzing and improving classroom lessons. In M. G. Sherin, V. R. Jacobs, \& Philipp, R. A. (Eds.), Mathematics Teacher Noticing: Seeing through Teachers' Eyes (pp. 152-168). New York: Routledge.

Santagata, R., Zannoni, C., \& Stigler, J. W. (2007). The role of lesson analysis in pre-service teacher education: an empirical investigation of teacher learning from a virtual videobased field experience. Journal of Mathematics Teacher Education, 10, 123-140. doi: $10.1007 / \mathrm{s} 10857-007-9029-9$

Schack, E. O., Fisher, M. H., Thomas, J. N., Eisenhardt, S., Tassell, J., \& Yoder, M. (2013). Prospective elementary school teachers' professional noticing of children's early numeracy. Journal of Mathematics Teacher Education, 16, 379-397. doi: $10.1007 / \mathrm{s} 10857-013-9240-9$

Sherin, M. G., Jacobs, V. R., \& Philipp, R. A. (2011). Situating the study of teacher noticing. In M. G. Sherin, V. R. Jacobs, \& R. A. Philipp (Eds.), Mathematics teacher noticing: Seeing through teachers' eyes (pp. 3-13). New York: Routledge.

Sherin, M. G., \& van Es, E. A. (2005). Using video to support teachers' ability to notice classroom interactions. Journal of Technology and Teacher Education, 13(3), 475-491.

Sherin, M. G., \& van Es, E. A. (2009). Effects of video club participation on teachers' professional vision. Journal of Teacher Education, 60, 20-37.

SportsTec. (1997-2016). Studiocode [Computer program]. Camarillo, CA: Vitigal Pty Limited.

Star, J. R., \& Strickland, S. K. (2008). Learning to observe: Using video to improve preservice mathematics teachers' ability to notice. Journal of Mathematics Teacher Education, 11(2), 107-125. doi: 10.1007/s10857-007-9063-7

van Es, E. A. (2011). A framework for learning to notice student thinking. A replication study. In 
M. G. Sherin, V. R. Jacobs, \& R. A. Philipp, R. A. (Eds.), Mathematics Teacher Noticing: Seeing through Teachers'Eyes (pp. 134-151). New York: Routledge.

van Es, E. A., \& Sherin, M. G. (2002). Learning to notice: Scaffolding new teachers’ interpretations of classroom interactions. Journal of Technology and Teacher Education, $10(4), 571-596$.

van Es, E. A., \& Sherin, M. G. (2008). Mathematics teachers' "learning to notice" in the context of a video club. Teaching and Teacher Education, 24(2), 244-276. doi: 10.1016/j.tate.2006.11.005

Vondrová, N., \& Žalská, J. (2015). Ability to notice mathematics specific phenomena: What exactly do student teachers attend to? Orbis scholae, 9(2), 77-101. doi: $10.14712 / 23363177.2015 .81$

Walkoe, J. (2015). Exploring teacher noticing of student algebraic thinking in a video club. Journal of Mathematics Teacher Education, 18(6), 523-550. doi: 10.1007/s10857-0149289-0. 


\section{Figure Captions}

Figure 1. Coding framework for the study.

Figure 2. Coding examples. 


\section{Acknowledgements}

This material is based upon work supported by [AGENCY]. Any opinions, findings, and conclusions or recommendations expressed in this material are those of the authors and do not necessarily reflect the views of the AGENCY.

Portions of this work appeared in the proceedings of XXX. 


\begin{tabular}{|l|l|ll|}
\hline \multicolumn{1}{|c|}{$\begin{array}{c}\text { Coding } \\
\text { Categories }\end{array}$} & \multicolumn{1}{|c|}{ Description } & \multicolumn{2}{c|}{ Codes } \\
\hline Agent (A) & $\begin{array}{l}\text { Who or what was the object } \\
\text { of the noticing }\end{array}$ & $\begin{array}{l}\text { Teacher (T) } \\
\text { Teacher/Student (T/S) } \\
\text { Student/Teacher (S/T) }\end{array}$ & $\begin{array}{l}\text { Student Group (Sg) } \\
\text { Individual Student (Si) } \\
\text { Math (M) }\end{array}$ \\
\hline $\begin{array}{l}\text { Specificity of } \\
\text { Mathematics } \\
\text { (MS) }\end{array}$ & $\begin{array}{l}\text { Whether and how the } \\
\text { mathematics in an instance } \\
\text { is discussed }\end{array}$ & $\begin{array}{l}\text { Non-math (NM) } \\
\text { General Math (GM) }\end{array}$ & Specific Math (SM) \\
\hline $\begin{array}{l}\text { Focus of } \\
\text { Noticing } \\
\text { (FoN) }\end{array}$ & $\begin{array}{l}\text { For instances with student } \\
\text { included in the agent, what } \\
\text { about the students was } \\
\text { attended to }\end{array}$ & $\begin{array}{l}\text { Affective Interaction (AI) } \\
\text { General Understanding (GU) } \\
\text { Mathematical Interaction (MI) }\end{array}$ & $\begin{array}{l}\text { Analyzing Student Math } \\
\text { (ASM) }\end{array}$ \\
\hline
\end{tabular}

${ }^{a}$ Student-teacher interactions were coded as Teacher/Student if the teacher was the primary focus and Student/Teacher if the student was the primary focus 


\begin{tabular}{|c|c|c|c|c|}
\hline & PT Description of Instance & $\mathbf{A}$ & MS & FoN \\
\hline 1 & This is the beginning of being able to use these variables as symbols. & $\mathrm{M}$ & GM & - \\
\hline 2 & Ensures that they all understand that adding something to its opposite is zero. & $\mathrm{T}$ & SM & - \\
\hline 3 & $\begin{array}{l}\text { [The teacher] gets the class engaged and guessing. A lot of students find it } \\
\text { difficult to throw answers out in the open where people might think they are dumb } \\
\text { if they are wrong. The teacher did a good job getting everyone involved. }\end{array}$ & $\mathrm{T} / \mathrm{S}$ & NM & AI \\
\hline 4 & $\begin{array}{l}\text { All agree that [the teacher] is wrong; shows they understand the concept of greater } \\
\text { than and less than with decimals. }\end{array}$ & $\mathrm{Sg}$ & SM & GU \\
\hline 5 & $\begin{array}{l}\text { I think this is another instance of building on student thinking. The teacher is } \\
\text { guiding them and asking the right questions to help initiate answers because they } \\
\text { are only } 7 \text { th graders, but I believe the students are kind of working together to } \\
\text { establish why you move the decimal two places to the left [when converting from } \\
\text { a percent to a decimal]. }\end{array}$ & $\mathrm{T} / \mathrm{S}$ & SM & MI \\
\hline 6 & $\begin{array}{l}\text { I think that this is a very good question that is necessary to further learning } \\
\text { (making examples similar). The student describes her question in depth to infer } \\
\text { her thinking. }\end{array}$ & $\mathrm{Si}$ & GM & NSM \\
\hline 7 & Student realizes that there is no opposite of zero with some help from teacher. & $\mathrm{S} / \mathrm{T}$ & SM & NSM \\
\hline 8 & $\begin{array}{l}\text { Student Math: } 5 \text { was the absolute value of }-5 \text { because it was the opposite } \\
\text { Point: the absolute value isn't always the opposite, but rather the distance from } \\
\text { zero (the absolute value of } 5 \text { isn't }-5 \text { ) } \\
\text { Appropriate: some other students may think the opposite of the negative numbers } \\
\text { is a good way to explain how they got their answers to the absolute values, but } \\
\text { that isn't always correct } \\
\text { Central: the lesson focuses on the fact that the absolute value is the distance from } \\
\text { zero } \\
\text { Opening/Timing: good to talk about while it is an issue }\end{array}$ & $\mathrm{Si}$ & SM & ASM \\
\hline 9 & $\begin{array}{l}\text { We can infer the student mathematics since the student does not understand the } \\
\text { definition of the inverse matrix. In other words, she does not know why we are } \\
\text { multiplying by } 1 / 2 \text { in one example and not the other. This is mathematically } \\
\text { significant to the lesson and creates a pedagogical opportunity since many } \\
\text { students do not comprehend when they have computed the inverse. The students } \\
\text { do not understand that they have to multiply by } 1 / \text { det[A]...I think a good question } \\
\text { to ask the class would be why we did not show the multiplication of } 1 / \text { det[A] in } \\
\text { the previous example or rather what det[A] would have to be for the inverse to } \\
\text { equal [d -b -c a]. That way, the students can build on this thought and learn that } \\
\text { when the det[A] }=1 \text {, we are multiplying the matrix [d -b -c a] by } 1 \text {, which is } \\
\text { trivial... The students should understand that if two matrices multiplied together } \\
\text { get the identity that they are inverses of each other. }\end{array}$ & $\mathrm{Si}$ & SM & ASM \\
\hline
\end{tabular}

